\title{
FAKTOR - FAKTOR PENGHAMBAT PELAYANAN DI TEMPAT PENDAFTARAN PASIEN BPJS RAWAT JALAN DI RUMAH SAKIT SARI MUTIARA, LUBUK PAKAM TAHUN 2019
}

\author{
Puput Melati Hutauruk, Meha Marito Br. Gurning \\ 1. Dosen Prodi D-III Perekam Dan Infokes Imelda, Jalan Bilal Nomor 52 Medan; 2.Alumni D-III Perekam \\ Dan Infokes Imelda \\ E-mail: ${ }^{1}$ Puputmelati.pm71@gmail.com \\ 2.
}

\begin{abstract}
ABSTRAK
Pelayanan rawat jalan (ambulatory services) adalah salah satu bentuk dari pelayanan kedokteran. Secara sederhana yang dimaksud dengan pelayanan rawat jalan adalah pelayanan kedokteran yang disediakan untuk pasien tidak untuk rawat inap (hospitalization). Penelitian ini bertujuan untuk mengetahui faktor - faktor penghambat pelayanan di tempat pendaftaran pasien BPJS rawat jalan di RSU Sari Mutiara Lubuk Pakam. Jenis penelitian ini menggunakan metode deskriptif dilaksan dengan sampel sebanyak 64 orang pasien BPJS rawat jalan. Dari hasil penelitian dari 64 orang pasien BPJS rawat jalan yang diteliti menunjukkan bahwa sebanyak 38 orang $(59,4 \%)$ telah mengetahui berkas pendaftaran pasien BPJS rawat jalan. Berdasarkan waktu penyediaan dokumen rekam medis didapatkan bahwa rata - rata waktu yang dibutuhkan untuk pendaftaran adalah 7 menit..Penyediaan dokumen rekam medis > 10 menit sebanyak 11 orang (17,2\%). Berdasarkan hasil penelitian tersebut, diharapkan agar selalu dilakukan keterbukaan atas informasi berkas persyaratan pendaftaran dan pelayanan kesehatan terhadap peserta BPJS Kesehatan. Bentuk penyimpanan dokumen rekam medis sebaiknya menggunakan dua sistem yaitu sentralisasi dan desentralisasi juga tracer agar keberadaan dokumen rekam medis dapat diketahui yaitu dipinjam atau sudah dikembalikan tetapi tidak sesuai dengan urutan nomor rekam medisnya.
\end{abstract}

Kata Kunci : Tempat pendaftaran, Pasien BPJS, Rawat jalan.

\section{PENDAHULUAN}

Menurut Permenkes No. 340/MENKES/PER/III/2010, Rumah Sakit adalah suatu bagian dari organisasi medis dan sosial yang mempunyai fungsi untuk memberikan pelayanan kesehatan lengkap kepada masyarakat, baik kuratif maupun preventif pelayanan keluarnya menjangkau keluarga dan lingkungan rumah. Rumah sakit juga merupakan pusat untuk latihan tenaga kesehatan dan penelitian biologi, psikologi, sosial ekonomi dan budaya.

Rumah sakit dapat memberikan pelayanan yang berdaya guna dan berhasil guna, maka dibutuhkan sebagai sumberdaya yang harus diatur dengan manajemen yang baik. Meningkatkan dan menjaga mutu pelayanan merupakan prioritas utama dalam manajemen pelayanan kesehatan rumah sakit. Pelayanan kesehatan harus memperhatikan mutu pelayanan untuk meningkatkan dan menentukan keberhasilan pelayanan kesehatan rumah sakit. Beberapa manfaat menjaga mutu antara lain dapat lebih meningkatkan efektifitas dan efisiensi pelayanan kesehatan, lebih meningkatkan penerimaan masyarakat terhadap pelayanan kesehatan dan dapat melindungi pelaksanaan kesehatan dari kemungkinan munculnya gugatan hukum (Sondari, 2015).

Menurut Permenkes

No. 269/MENKES/PER/III/2008 tentang rekam medis, bahwa rekam medis adalah berkas yang berisikan catatan dan dokumen tentang identitas pasien pemeriksaan, pengobatan, 
tindakan dan pelayanan lain yang telah diberikan kepada pasien selama masa perawatan yang memuat pengetahuan pasien dan pelayanan yang diperolehnya serta memuat informasi yang cukup untuk mengidentifikasi pasien, memberikan diagnosis dan pengobatan serta merekam hasilnya (Azrul, 2006).

Waktu penyediaan dokumen rekam medis pasien rawat jalan berdasarkan Menkes tentang Standar Pelayanan Minimal (SPM) di rumah sakit adalah kurang dari 10 menit dihitung mulai dari saat pasien selesai registrasi sampai dokumen rekam medis tersebut sampai di poliklinik yang dituju (Kemenkes, 2013).

Instalasi Rawat Jalan (IRJ) merupakan unit fungsional yang menangani penerima pasien di rumah sakit yang berobat jalan di rumah sakit. Pemberian pelayanan di IRJ pertama dilakukan di tempat pendaftaran pasien rawat jalan (TPPRI) merupakan salah satu bagian pelayanan kesehatan yang menangani penerimaan pasien, baik yang akan berobat jalan maupun yang akan dirawat inap di rumah sakit yang dikelola oleh petugas rekam medis. Oleh karena itu tugas dari seorang perekam medis adalah memberikan pelayanan sebaik-baiknya kepada pasien sehingga pasien merasa puas akan pelayanan yang di berikan oleh petugas rekam medis tersebut.

Undang - Undang No. 24 Tahun 2012 menetapkan, Jaminan Sosial Nasional akan diselenggarakan oleh BPJS, terdiri atas BPJS Kesehatan Kesehatan dan BPJS Ketenagakerjaan. Implementasi program JKN oleh BPJS kesehatan dimulai sejak 1 Januari 2014 (UU SJSN, 2012). Sebelum JKN, tidak semua kasus yang akan dirujuk dikonfirmasikan terlebih dahulu ke RSUD, namun pada era JKN dengan semakin ketatnya aturan-aturan JKN tentang ketentuan indikasi rujuk, rumah sakit rujukan semakin selektif dalam menerima pasien -pasien rujukan, sehingga komunikasi sebelum merujuk pasien pun terus menerus diintensifkan. Hal ini menunjukan bahwa keberadaan JKN membawa pengaruh yang baik terhadap sistem komunikasi yang dilakukan sebelum merujuk pasien, yakni menjaga kesinambungan pelayanan sesuai dengan yang diharapkan dalam JKN.

Berdasarkan latar belakang dan hasil survei awal di Rumah Sakit Sari Mutiara Lubuk Pakam menunjukkan bahwa pasien BPJS rawat jalan mengalami hambatan untuk mendapatkan pelayanan di tempat pendaftaran. Hal ini disebutkan pasien lupa membawa Kartu beserta BPJS Kesehatan, Surat Rujukan, Kartu Keluarga (KK), Kartu Tanda Pendudduk ( KTP), Oleh karena itu penulis tertarik mengambil judul tentang ''Faktor - Faktor Penghambat Pelayanan Di tempat Pendaftaran Pasien BPJS Rawat Jalan di RSU Sari Mutiara Lubuk Pakam'.

\section{Tujuan Penelitian}

Untuk mengetahui faktor-faktor penghambat pelayanan di tempat pendaftaran pasien BPJS rawat jalan di RSU Sari Mutiara Lubuk Pakam.

\section{METODE}

Jenis penelitian ini menggunakan metode deskriptif yang menggambarkan apa saja faktor - faktor penghambat pelayanan di tempat pendaftaran pasien BPJS rawat jalan di RSU Sari Mutiara Lubuk Pakam berdasarkan observasi. Penelitian dilaksanakan pada 6 Mei 2019 sampai dengan 10 Mei 2019. Penelitian dilakukan di Rumah Sakit Sari Mutiara Lubuk Pakam di Jl. Medan, Kecamatan Lubuk Pakam, Kabupaten Deli Serdang, Provinsi Sumatera Utara.

Menurut Notoadmojo (2010), populasi merupakan keseluruhan atau totalitas objek yang diteliti yang ciri - cirinya akan diduga atau ditaksir (estimated). Populasi pada penelitian ini adalah seluruh pasien BPJS rawat jalan yang mendapatkan pelayanan di tempat pendaftaran di Rumah Sakit Sari Mutiara, Lubuk Pakam pada tanggal $6-10$ Mei 2019. Berdasarkan data bulan Januari, Februari dan Maret tahun 2019 rata - rata jumlah pasien rawat jalan peserta BPJS per bulan di RSU Sari Mutiara, Lubuk Pakam adalah 5227 pasien dan rata - rata jumlah kunjungan 1 hari adalah 174 pasien.

Metode sampling yang digunakan adalah teknik accidental sampling, peneliti 
mengumpulkan data dari subyek yang kebetulan ditemuinya pada saat pengumpulan data dilakukan. Proses diperolehnya sampel semacam ini disebut sebagai penarikan sampel secara kebetulan (Notoatmodjo, 2010).

Sampel pada penelitian ini adalah pasien BPJS rawat jalan yang mendapatkan pelayanan di tempat pendaftaran di Rumah Sakit Sari Mutiara, Lubuk Pakam pada tanggal 6-10 Mei 2019. Menurut (Bambang dan Lina, 2013), sebuah rumus yang dapat digunakan untuk menentukan besaran sampel yaitu rumus Slovin.

$\mathrm{n}=\frac{\mathrm{N}}{1+\mathrm{N}\left(\mathrm{e}^{2}\right)}$

$\mathrm{n}=$ Besar sampel

$\mathrm{N}=$ Jumlah populasi

$\mathrm{e}=$ Konstanta $=0,1$ yaitu penyimpangan terhadap populasi atau derajat ketepatan yang diinginkan sebesar 0,1

$$
\begin{aligned}
\text { Besar sampel } & =\frac{174}{1+174(0,1)^{2}} \\
& =64 \text { orang }
\end{aligned}
$$

Jadi, jumlah sampel pada penelitian ini adalah 64 orang.

Variabel adalah sesuatu yang digunakan sebagai ciri, sifat atau ukuran yang dimiliki atau didapat oleh satuan penelitian tentang sesuatu konsep pengertian tertentu (Notoatmodjo, 2010). Variabel independen adalah dalam bahasa Indonesia sering disebut sebagai variabel bebas. Variabel ini mempengaruhi atau yang menjadi sebab perubahannya atau timbulnya variabel dependen. Variabel dependen sering disebut sebagai variabel output, kriteria dan konsekuen. Dalam bahasa Indonesia sering disebut sebagai variabel terikat. Variabel terikat merupakan variabel yang dipengaruhi atau yang menjadi akibat, karena adanya variabel bebas (Noor, 2012).

Adapun variabel-variabel yang akan diamati oleh peneliti adalah :

1. Variabel independen

a. Persyaratan pendaftaran pasien BPJS rawat jalan.

b. Waktu penyediaan dokumen rekam medis.

2. Variabel dependen

a. SOP alur pendaftaran pasien BPJS rawat jalan.

b. Pendidikan dan pengalaman sumber daya manusia (petugas rekam medis).

\section{Defenisi Operasional}

Untuk membatasi ruang lingkup atau pengertian variabel - variable yang diteliti /diamati, perlu sekali diberi batasan atau

\begin{tabular}{|c|c|c|c|c|}
\hline Variabel & Defenisi & Alat Ukur & Cara Ukur & Satuan Variabel \\
\hline $\begin{array}{l}\text { 1. Kelengkapan } \\
\text { berkas } \\
\text { pendaftaran } \\
\text { pasien BPJS }\end{array}$ & $\begin{array}{l}\text { Berkas-berkas yang } \\
\text { harus dibawa pasien } \\
\text { BPJS saat mendaftar } \\
\text { sesuai dengan SOP yaitu } \\
\text { Kartu kepesertaan BPJS, } \\
\text { Surat rujukan, KTP dan } \\
\text { Kartu keluarga }\end{array}$ & $\begin{array}{l}\text { Lembar } \\
\text { observasi }\end{array}$ & Observasi & $\begin{array}{l}\text { 1. Lengkap } \\
\text { 2. Tidak lengkap }\end{array}$ \\
\hline $\begin{array}{l}\text { 2. Waktu } \\
\text { penyediaan } \\
\text { dokumen rekam } \\
\text { medis }\end{array}$ & $\begin{array}{l}\text { Meliputi pencatatan data } \\
\text { pasien, penomoran } \\
\text { dokumen, penyimpanan } \\
\text { dan r pengambilan } \\
\text { kembali dokumen rekam } \\
\text { medis }\end{array}$ & $\begin{array}{l}\text { Lembar } \\
\text { observasi }\end{array}$ & Observasi & $\begin{array}{l}\text { 1. > } 10 \text { menit } \\
\text { 2. }<\text { dari } 10 \text { menit }\end{array}$ \\
\hline
\end{tabular}
defenisi operasional (Notoadmojo, 2010).

Tabel 1. Defenisi Operasional

\section{Instrumen Penelitian}

Alat pengumpul data pada penelitian ini yaitu :

- Lembar observasi.

- Stopwatch / Jam pada komputer di tempat pendaftaran.

\section{Cara Pengumpulan Data}

Pengamatan dan observasi adalah salah satu kegiatan dari makhluk hidup yang terdiri menerima pengetahuan tentang dunia luar melalui indera, atau pencatatan data menggunakan instrument lembar catatan. 
HASIL

\section{Kelengkapan Berkas Pendaftaran Pasien BPJS}

Dari hasil observasi didapatkan kelengkapan berkas pendaftaran pasien BPJS sebagai berikut:

Tabel 2. Kelengkapan Berkas Pendaftaran Pasien BPJS

\begin{tabular}{cccc}
\hline No & Keterangan & f & Persentase (\%) \\
\hline 1 & Lengkap & 38 & 59,4 \\
\hline 2 & Tidak lengkap & 26 & 40,6 \\
\hline & Jumlah & $\mathbf{6 4}$ & $\mathbf{1 0 0}$ \\
\hline
\end{tabular}

Berdasarkan tabel di atas diketahui bahwa pasien BPJS rawat jalan yang telah lengkap berkas pendaftaran adalah sebanyak 38 orang dengan persentase 59,4 $\%$ dan yang tidak lengkap sebanyak 26 orang dengan persentase $40,6 \%$.
Tabel 3. Berkas Pendaftaran Yang Tidak Lengkap

\begin{tabular}{ccrc}
\hline No & \multicolumn{1}{c}{ Keterangan } & f & $(\boldsymbol{\%})$ \\
\hline 1 & Tidak membawa surat rujukan & 13 & 50,0 \\
\hline 2 & Tidak membawa KTP & 10 & 38,5 \\
\hline 3 & Tidak membawa surat control & 3 & 11,5 \\
\hline & Jumlah & $\mathbf{2 6}$ & $\mathbf{1 0 0}$ \\
\hline
\end{tabular}

Berdasarkan tabel di atas diketahui bahwa pasien BPJS rawat jalan yang tidak lengkap berkas pendaftaran terbanyak adalah tidak membawa surat rujukan yaitu sebanyak 13 orang dengan persentase 50,0 $\%$ dan yang paling sedikit yaitu tidak membawa surat control yaitu sebanyak 3 orang dengan persentase $11,5 \%$.

\section{Waktu Penyediaan Dokumen Rekam Medis}

Waktu penyediaan dokumen rekam medis paling lambat sesuai dengan SOP adalah 10 menit. Dari hasil observasi didapatkan waktu penyediaan dokumen rekam medis sebagai berikut:

Tabel 4. Waktu Penyediaan Dokumen Rekam Medis

\begin{tabular}{ccccc}
\hline No & Nomor RM & $\begin{array}{c}\text { Waktu Pasien Datang } \\
\text { Mendaftar }\end{array}$ & $\begin{array}{c}\text { Waktu Pasien Selesai } \\
\text { Mendaftar }\end{array}$ & $\begin{array}{c}\text { Waktu Penyediaan } \\
\text { Rekam Medis }\end{array}$ \\
\hline 1 & 063395 & 08.05 & 08.12 & 7 menit \\
\hline 2 & 036563 & 08.08 & 08.10 & 3 menit \\
\hline 3 & 046588 & 08.15 & 08.23 & 8 menit \\
\hline 4 & 012789 & 08.16 & 08.25 & 9 menit \\
\hline 5 & 069102 & 09.40 & 09.47 & 7 menit \\
\hline 6 & 035636 & 10.20 & 10.25 & 25 menit \\
\hline 7 & 034607 & 10.30 & 10.55 & 8 menit \\
\hline 8 & 024867 & 12.30 & 12.38 & 8 menit \\
\hline 9 & 035886 & 08.10 & 08.18 & 7 menit \\
\hline 10 & 062774 & 09.18 & 09.25 & 5 menit \\
\hline 11 & 018216 & 08.15 & 08.20 & 9 menit \\
\hline 12 & 028338 & 10.16 & 10.25 & 20 menit \\
\hline 13 & 060915 & 09.40 & 10.05 & 5 menit \\
\hline 14 & 062204 & 10.20 & 11.25 & 6 menit \\
\hline 15 & 052179 & 10.30 & 11.37 & 7 menit \\
\hline 16 & 056671 & 11.30 & 11.36 & 6 menit \\
\hline 17 & 037097 & 09.18 & 09.25 & 9 menit \\
\hline 18 & 049227 & 08.15 & 08.21 & 5 menit \\
\hline 19 & 039936 & 10.16 & 10.25 & 5 menit \\
\hline 20 & 029462 & 09.40 & 09.45 & 27 menit \\
\hline 21 & 060908 & 10.20 & 10.25 & 8 menit \\
\hline 22 & 047486 & 09.18 & 09.45 & 7 menit \\
\hline 23 & 051839 & 08.15 & 08.23 & 7 menit \\
\hline 24 & 021738 & 10.16 & 10.35 & 5 menit \\
\hline 25 & 061595 & 08.25 & 08.32 & \\
\hline 26 & 016322 & 08.18 & 08.25 & 08.20 \\
\hline 27 & 012936 & 08.15 & & \\
\hline & & & & \\
\hline
\end{tabular}




\begin{tabular}{|c|c|c|c|c|}
\hline 28 & 066368 & 08.16 & 08.25 & 9 menit \\
\hline 29 & 024663 & 09.40 & 09.45 & 5 menit \\
\hline 30 & 030612 & 10.20 & 10.25 & 5 menit \\
\hline 31 & 046612 & 10.30 & 10.41 & 11 menit \\
\hline 32 & 059752 & 11.30 & 11.55 & 25 menit \\
\hline 33 & 066444 & 09.18 & 09.45 & 7 menit \\
\hline 34 & 066386 & 08.15 & 08.23 & 8 menit \\
\hline 35 & 062801 & 10.16 & 10.25 & 9 menit \\
\hline 36 & 044315 & 09.37 & 09.45 & 8 menit \\
\hline 37 & 023531 & 09.40 & 09.46 & 6 menit \\
\hline 38 & 038432 & 10.20 & 10.45 & 25 menit \\
\hline 39 & 010298 & 10.30 & 10.36 & 6 menit \\
\hline 40 & 027752 & 11.10 & 11.15 & 5 menit \\
\hline 41 & 042243 & 08.15 & 08.24 & 9 menit \\
\hline 42 & 050122 & 08.15 & 08.20 & 5 menit \\
\hline 43 & 035318 & 08.16 & 08.23 & 7 menit \\
\hline 44 & 015373 & 09.40 & 09.45 & 5 menit \\
\hline 45 & 058951 & 10.20 & 10.25 & 5 menit \\
\hline 46 & 045632 & 10.30 & 11.00 & 30 menit \\
\hline 47 & 026577 & 11.30 & 11.33 & 3 menit \\
\hline 48 & 018689 & 08.10 & 08.28 & 18 menit \\
\hline 49 & 029312 & 09.18 & 09.25 & 7 menit \\
\hline 50 & 025949 & 08.15 & 08.23 & 8 menit \\
\hline 51 & 015415 & 08.16 & 08.25 & 9 menit \\
\hline 52 & 068179 & 09.40 & 09.45 & 5 menit \\
\hline 53 & 010953 & 10.20 & 11.35 & 15 menit \\
\hline 54 & 067258 & 10.30 & 10.34 & 4 menit \\
\hline 55 & 061452 & 11.05 & 11.13 & 8 menit \\
\hline 56 & 064505 & 09.18 & 09.25 & 7 menit \\
\hline 57 & 035824 & 08.15 & 08.18 & 3 menit \\
\hline 58 & 016129 & 10.16 & 10.22 & 6 menit \\
\hline 59 & 047888 & 09.40 & 09.55 & 15 menit \\
\hline 60 & 069017 & 10.20 & 10.25 & 5 menit \\
\hline 61 & 026993 & 09.18 & 09.25 & 7 menit \\
\hline 62 & 040088 & 08.15 & 08.20 & 5 menit \\
\hline 63 & 027363 & 10.16 & 10.25 & 9 menit \\
\hline 64 & 062137 & 08.25 & 08.31 & 6 menit \\
\hline \multicolumn{4}{|c|}{ Rata - rata } & 7 menit \\
\hline
\end{tabular}

Berdasarkan tabel di atas dapat diketahui bahwa rata-rata waktu penyediaan dokumen rekam medis selama 7 menit.

Tabel 5. Waktu Penyediaan Dokumen Rekam Medis

\begin{tabular}{cccc}
\hline No & Keterangan & f & Persentase (\%) \\
\hline 1 & $<10$ menit & 53 & 82,8 \\
\hline 2 & $>10$ menit & 11 & 17,2 \\
\hline & Jumlah & $\mathbf{6 4}$ & $\mathbf{1 0 0}$ \\
\hline
\end{tabular}

Berdasarkan tabel di atas dapat diketahui waktu penyediaan dokumen rekam medis < 10 menit adalah sebanyak 53 orang dengan persentase $82,8 \%$ dan $>10$ menit adalah sebanyak 11 orang dengan persentase $17,2 \%$.

\section{PEMBAHASAN}

\section{Kelengkapan Berkas Pendaftaran Pasien BPJS}

Dari hasil penelitian diketahui bahwa pasien BPJS rawat jalan yang telah lengkap berkas pendaftaran adalah sebanyak 38 orang dengan persentase $59,4 \%$ dan yang tidak lengkap sebanyak 26 orang dengan persentase 40,6\%. Diketahui bahwa dari 26 orang pasien BPJS rawat jalan yang tidak lengkap terbanyak yaitu tidak membawa 
surat rujukan adalah sebanyak 13 orang dengan persentase $50 \%$ dan yang paling sedikit yaitu tidak membawa surat kontrol adalah 3 orang dengan persentase $11,5 \%$.

Dengan memperhatikan data diatas bahwa telah banyak masyarakat yang mengetahui berkas pendaftaran pasien BPJS yang harus dibawa saat mendaftar untuk berobat. Adapun yang menghambat pelayanan di tempat pendaftaran dikarenakan berkas persyaratan pendaftaran pasien BPJS yang tidak lengkap kebanyakan tidak membawa surat rujukan. Hal ini sesuai dengan pernyatan Kemenkes (2013) yang menyatakan bahwa salah satu prosedur pendaftaran pasien BPJS adalah peserta melakukan pendaftaran ke rumah sakit dengan membawa kartu identitas, kartu kepesertaan BPJS Kesehatan serta surat rujukan atau surat kontrol.

\section{Waktu Penyediaan Dokumen Rekam Medis}

Dari hasil penelitian diketahui bahwa rata - rata waktu penyediaan rekam medis adalah 7 menit. Waktu penyediaan dokumen rekam medis < 10 menit adalah sebanyak 53 orang dengan persentase $82,5 \%$ dan $>10$ menit adalah sebanyak 11 orang dengan persentase $17,2 \%$.

Dari hasil observasi diketahui bahwa penyebab waktu penyediaan dokumen rekam medis > 10 menit adalah dokumen rekam medis pasien yang sulit ditemukan dikarenakan penyimpanan dan pendataan peminjaman dokumen yang tidak tersusun rapi dan tidak ada tracer juga adanya pasien yang tidak mengetahui alur pendaftaran pasien BPJS sehingga menyebabkan harus mengarahkan kembali pasien agar mendaftar sesuai alur pendaftaran.

Hal ini sesuai dengan hasil penelitian (Nova, 2017) didapatkan bahwa mayoritas rekam medis sulit ditemukan, penyebab diantaranya adalah berkas rekam medis tidak tersusun rapi didalam rak penyimpanan, tidak adanya tracer sehingga berkas tersebut tidak diketahui keberadaannya yaitu dipinjam atau sudah dikembalikan tetapi tidak sesuai dengan urutan nomor rekam medisnya.
Waktu penyediaan dokumen rekam medis pasien rawat jalan berdasarkan Menkes (2013) tentang Standar Pelayanan Minimal (SPM) di rumah sakit adalah kurang dari 10 menit dihitung mulai dari saat pasien selesai registrasi sampai dokumen rekam medis tersebut sampai di poliklinik yang dituju.

\section{KESIMPULAN}

Dari hasil yang diperoleh pada penelitian dapat diambil kesimpulan sebagai berikut :

1. Pasien BPJS rawat jalan yang telah lengkap berkas pendaftaran adalah 38 orang $(59,4 \%)$ lengkap menunjukkan bahwa telah banyak masyarakat yang mengetahui syarat pendaftaran pasien BPJS dan Pasien BPJS rawat jalan yang tidak lengkap berkas pendaftaran adalah 26 orang $(40,6 \%)$ tidak lengkap menunjukkan bahwa telah banyak masyarakat tidak memenuhi persyaratan pendaftaran pasien BJS.

2. Dari 38 orang pasien BPJS rawat jalan yang tidak lengkap berkas pendaftaran yang diteliti diketahui bahwa berkas yang tidak lengkap terbanyak adalah tidak membawa surat rujukan yaitu sebanyak 13 orang $(50,0 \%)$ dan yang paling sedikit pasien BPJS tidak membawa surat control yaitu sebanyak 3 orang $(11,5 \%)$ tidak lengkap menunjukkan bahwa pasien tidak membawa surat rujukan.

3. Berdasarkan waktu penyediaan dokumen rekam medis didapatkan bahwa rata rata waktu yang dibutuhkan untuk pendaftaran adalah 7 menit.

4. Penyediaan dokumen rekam medis $>10$ menit sebanyak 11 orang $(17,2 \%)$ dikarenakan dokumen rekam medis sulit ditemukan dan adanya pasien yang belum mengetahui alur pendaftaran sehingga harus diarahkan kembali.

\section{SARAN}

Berdasarkan kesimpulan diatas, disarankan kepada pihak yaitu :

1. Institusi Pendidikan 
Diharapkan sebagai refensi dalam mengembangkan materi perkuliahan dan revisi kurikulum sesuai dengan tuntutan lahan praktek dan menambah wawasan perekam medis dan informasi kesehatan bahwa rekam medis sangat penting perannya diRumah Sakit dan sebagai bahan pembelajaran dan pengaplikasikan ilmu tentang pelayanan ditempat pendaftaran pasien BPJS rawat jalan.

2. Bagi Pasien

Diharapkan kepada seluruh pasien agar membawa syarat-syarat untuk mendaftar pasien BPJS rawat jalan seperti Surat rujukan, kartu pesertaBPJS Kesehatan, Kartu Tanda Penduduk (KTP), Kartu Keluarga (KK) dan Surat kontrol.

3. Orang yang di Teliti

Diharapkan agar semakin baik ditempat pendaftaran pasien BPJS rawat jalan.

4. Peneliti Selanjutnya

Diharapkan kepada peneliti selanjutnya melakukan penelitian lanjutan tentang Analisi Penghambat Pelayanan di Tempat Pendaftaran Pasien BPJS rawat jalan diRumah Sakit Sari Mutiara Lubuk Pakam.

5. Bagi Rumah Sakit.

Penulis berharap hasil penelitian ini dapat masukan bagi rumah sakit bahan evaluasi dalam meningkatkan mutu pelayanan ditempat pendaftaran pasien BPJS rawat jalan.

\section{DAFTAR PUSTAKA}

Azwar, Azrul. (2006). Pengantar Administrasi Kesehatan. Jakarta: Binarupa Aksara.

Darlis. (2012). Penelitian Ilmiah: Tinjauan Waktu Tunggu Pelayanan Rekam Medis Di Pendaftaran Rawat Jalan Rumah Sakit Umum Daerah Dr. H. Yuliddin Away Tapaktuan Kabupaten Aceh Selatan Tahun 2012. Aceh: Universitas Meulaboh-Aceh.
Depkes RI. (2012). Peta Jalan Menuju Jaminan Kesehatan Nasional 20122019. Jakarta: Depkes RI.

Depkes RI. (2014). Buku Pegangan Sosialisasi Jaminan Kesehatan Nasional (JKN) dalam Sistem Jaminan Sosial Nasional (SJSN). Jakarta: Depkes RI.

Manjary, 1. A. (2015). Kepuasan pasien BPJS Rawat Jalan Terhadap Pelayanan di Rumah Sakit Tugurejo. Semarang: UDINUS.

Noor, Juliansyah. (2012). Metodologi Penelitian. Jakarta:Kencana Prenada Medika.

Notoadmotjo, S. (2010). Metodologi Penelitian Kesehatan. Jakarta: Rineka Cipta.

Nova. (2017). Penelitian Ilmiah: Analisis Faktor Yang Mempengaruhi Waktu Tunggu Pelayanan di Rekam Medis Rawat Jalan (Studi di Rekam Medis Rawat Jalan RSU Haji Surabaya). Surabaya: Universitas Airlangga.

Permenkes Republik Indonesia Nomor 340/ Menkes/ III/. (2010). Tentang Klasifikasi Rumah Sakit. Jakarta: Departemen Kesehatan RI.

Permenkes RI No. 269/ MENKES/PER/111/. (2008). Tentang Rekam Medis. Jakarta: Departemen Kesehatan RI.

Pujiono, Agus. (2015). Karya Tulis Ilmiah: Pengetahuan Peserta BPJS Tentang Alur Prosedur Pelayanan Pasien Rawat Jalan RSUP dr. Kariadi.

Sondari, Aer. (2015). Analisis Kepuasan Pasien Rawat Jalan Peserta Jaminan Kesehatan Nasional (JKN) di Rumah Sakit Umum Daerah. Brebes: UNNES.

Undang - Undang Nomor 24 Tahun 2011. (2011). Tentang Badan Penyelenggara Jaminan Sosial (BPJS).Jakarta: Departemen Kesehatan RI. 